\title{
Equidad de género en la reforma político-electoral de la constitución mexicana (20I4)
}

\section{María Teresa Guzmán Robledo}

\section{Resumen}

El presente estudio no sólo aborda la reforma constitucional en materia político electoral, promulgada por el Presidente de la República, el día 31 de enero de 2014, la cual entre otros aspectos prevé que los partidos políticos deberán garantizar la paridad entre géneros en candidaturas a legisladores federales y locales, sino que además elabora un breve análisis del desarrollo de la participación de la mujer en la vida política en el Estado mexicano, iniciando por el análisis de los antecedentes del derecho de igualdad, así como de los primeros escritos jurídicos de la desigualdad entre el hombre y la mujer, dando paso al estudio del "principio de igualdad", para posteriormente analizar aspectos relevantes de la equidad de género en la materia político-electoral, tanto a nivel nacional como internacional.

Palabras clave: igualdad; discriminación; cuotas; paridad; democracia; participación efectiva.

\begin{abstract}
This study addresses not only the constitutional reform in electoral political matters, promulgated by the President of the Republic on January 31, 2014, which among other aspects, foresees the guarantee from political parties of parity between genders in applications for local and federal legislators; but also process a brief analysis of the development of participation in political life for women in the Mexican state, starting with the analysis of the background of the right to equality, as well as the first legal writings of inequality between men and women, giving a way to the study of the "principle of equality", to later analyze relevant aspects of gender equity in electoral political matters, both nationally and internationally.
\end{abstract}

Keywords: equality; discrimination; quota; parity; democracy; effective participation.

Artigo recebido em 14 de janeiro de 20I5; aceito para publicação em 24 de maio de 2015.

\section{Acerca de la autora}

Profesora académica de la División de Estudios Jurídicos de la Universidad de Guadalajara, Jalisco. 


\section{Introducción}

Para hablar de equidad de género, tenemos que comenzar abordando este último concepto desde el principio, desde su nacimiento, como el concepto que alude a la diferenciación sexual inscrita en la estructura física de los individuos, el cual se deriva de la biología. Sin embargo, actualmente género se relaciona con los diversos significados que cada sociedad le atribuye al vocablo, esto es, que puede referirse a otras disciplinas, como la sociología, psicología, antropología, ciencia política, historia o cualquier otra rama del conocimiento, lo que ha permitido descubrir las normas, representaciones, ideas y comportamientos que se han definido socialmente como "naturales" y que son atribuidas a las diferencias biológicas de los sexos.

El género es producto de una construcción cultural que incide desde la infancia de una diferenciación que asigna un "status sexual" de género, basándose en las distintas representaciones sobre las conductas, maneras e ideas apropiadas, que terminan por definir la masculinidad o la feminidad de cada individuo.

Tanto los hombres como las mujeres presentan un conjunto de características adquiridas mediante el aprendizaje, que los condicionan a desarrollar ciertas actitudes. Los diversos modos de sentir, pensar y comportarse de los sexos son atribuibles a las construcciones o condicionamientos sociales y familiares que de manera diferenciada se le asignan a los hombres y mujeres (Cazarin, 2011, 13).

Por lo que, se ha definido la equidad de género como un principio que, conscientes de la desigualdad existente entre mujeres y hombres, permite el acceso con justicia e igualdad de condiciones al uso, control, aprovechamiento y beneficio de los bienes, servicios, oportunidades y recompensas de la sociedad, lo anterior con el fin de lograr la participación de las mujeres en la toma de decisiones en todos los ámbitos de la vida social, económica, política, cultural y familiar.

En la última reforma constitucional se dio un paso decisivo para eliminar la legendaria discriminación de la mujer que ha existido en el ámbito político-electoral, en especial, en la participación activa de la mujer en la vida política del país, su derecho a ser votada en cargos de elección popular, en igualdad de condiciones con los hombres, con una paridad de género al $50 \%$. 
En el presente trabajo no sólo se pretende llevar a cabo un estudio de esta relevante reforma constitucional en materia político-electoral, a través de la cual, entre otras cuestiones, se abordó la equidad de género, sino que también se llevará a cabo un estudio general de los antecedentes del derecho de igualdad, para posteriormente abordar de manera breve la historia escrita de la desigualdad entre el hombre y la mujer; dando paso al análisis del "Principio de Igualdad" tomado de Ferrajoli; asimismo se realizará un estudio del como nuestra Constitución Federal aborda en su artículo primero el derecho a no ser discriminado; sin dejar de lado el derecho internacional de los derechos humanos, dado que los instrumentos internacionales en materia de derechos humanos han representado el marco del desarrollo de los derechos de igualdad entre el hombre y la mujer; entre otras cuestiones que a continuación se abordan.

\section{El proceso de generalización, línea de evolución del derecho a la igualdad del sufragio}

Hablar de desigualdad o diferencias en el ejercicio del derecho activo y pasivo al sufragio, no sólo ha sido un tema de géneros. En el presente punto abordaremos los antecedentes del reconocimiento de los derechos de igualdad, en los que se encuentra el derecho al sufragio, por lo que, antes de entrar al estudio de los antecedentes de la discriminación de la mujer en el ámbito político-electoral, analizaremos el desarrollo histórico de la evolución de dicho derecho, estudiando los contenidos y el sentido que tienen las aportaciones sucesivas, liberal, democrática y socialista, que permiten entender en su integridad a los derechos de igualdad, tomando como base el análisis realizado por el autor Peces-Barba (2004, 103-128).

Como antecedente general al derecho de igualdad al voto, la generalización consistirá en el progresivo, aunque no definitivo, ajuste entre las afirmaciones de que los derechos son naturales (que corresponden a todos los seres humanos), y una práctica restrictiva que ceñía su disfrute a una clase social (la burguesía).

La generalización supondrá la aceptación de la inicial categoría liberal de los derechos, como capaz de trascender su origen histórico, y los intereses que lo engendraron (el arranque inicial de los derechos que impulso una formula general y abstracta que correspondía a un goce, excluyente en la realidad, de extensas categorías de ciudadanos, 
planteamiento al que correspondió la negación liberal), para convertirse en una instancia valida, con un tenor racional suficientemente generalizable para servir a la realización de la autonomía moral, máxima expresión de la dignidad humana. Esta línea enfrentara a quienes como Marx, y Lenin entre otros, pensaban que se trataba de una categoría esclava de la ideología burguesa, con el proceso de generalización y con los sectores liberales, democráticos y socialistas que la propugnaban. Siendo con probabilidad el proceso central que perfila la identificación de los derechos fundamentales, dado a sus orígenes, el impulso que tuvo y obteniendo como resultado la creación de nuevos derechos, que a continuación se aborda su análisis.

\section{Los orígenes de la generalización}

Las primeras formulaciones históricas de los derechos como derechos naturales partían de la igualdad natural de todos los seres humanos (por influencia del iusnaturalismo), y por consiguiente, de la consideración de todos como titulares; nos referimos al modelo americano y al modelo francés. En el inglés, la forma historicista y pragmática de los derechos fundamentales influirá en que el proceso de generalización parta también de los textos concretos. Empero, esta generalidad de los destinatarios titulares de los derechos no correspondía con la realidad, ni con el carácter indefinido de los contenidos, como en el caso de la propiedad, que es de imposible contenido igualitario. Por otra parte, derechos claves no se consideraban, y estaban excluidos del elenco de los recogidos en las Declaraciones. Es el caso del derecho de asociación, que incluso se prohíbe en Francia con la Ley Le Chapellier, de 14 de Junio de 1791. Lo mismo ocurre con el derecho de sufragio, del que no todas las personas eran titulares, y con las declaraciones de derechos naturales iguales para todos, limitado a algunas categorías de ciudadanos por razones económicas o culturales.

La razón que explica el proceso de generalización es el desajuste entre unas declaraciones de igualdad natural de los hombres en la titularidad de los derechos, y una realidad que negaba el derecho de sufragio a una parte de la población, así como el derecho de asociación política y sindical, y que contrario a ello exaltaba como primero de los derechos al de propiedad, que justificaba su existencia en su detentación por una minoría y que era de imposible extensión 
a todos, por razones de escasez. En el seno de este movimiento, y desde una mentalidad de igualación efectiva en el ejercicio de los derechos, se debe también situar la aparición de los derechos económicos, sociales y culturales, como indispensables para el goce generalizado de los derechos civiles y políticos.

\section{El impulso de la generalización}

El punto de encuentro del liberalismo y del socialismo será la democracia. Para los liberales democráticos, el socialismo, como expresión del movimiento obrero, no es una realidad a destruir, sino un fenómeno positivo a integrar. Y para los socialistas democráticos, el estado de derecho, el sistema parlamentario representativo y los derechos fundamentales no son instituciones esencialmente burguesas, sino de origen histórico burgués, y son adecuadas para realizar desde ellas los ideales socialistas. Construyéndose de esta manera en el pensamiento liberal una nueva generación de derechos, sin que en esta existiera intereses de clases y desigualdad entre ellos.

\section{Los resultados del proceso de generalización}

Se refiere al nacimiento de nuevos derechos respecto del proceso de generalización, los cuales se pueden distinguir en tres dimensiones: a) Los derechos que hacen posible la participación política igualitaria; b) La configuración de una nueva generación de derechos fundamentales para asegurar la solidaridad y la igualdad; y c) La desfundamentalización del derecho de propiedad.

Los derechos relativos a la participación son el derecho de asociación y el sufragio universal. De los cuales el primero tendrá una repercusión en el ámbito político y también en el sindical, y será el origen de los partidos, de los sindicatos, y de las asociaciones para otros fines, culturales, deportivos, etc. El sufragio universal permitirá la incidencia de esa participación en la formación de los órganos públicos encargados de expresar la voluntad estatal, a través del derecho, permitiendo superar la idea excluyente de que en la formación del interés general debían participar solamente los sectores económica y culturalmente independientes; también permitirá la función de integración en el Parlamento de todas las ideologías y sectores sociales que acepten las reglas de juego. Y como tal consecuencia, se 
incorporaran al Parlamento representantes de los partidos obreros que defenderán sus intereses y que plantearan problemas ajenos a los que tradicionalmente interesaban a la burguesía, y esta dinámica, que llevará a la formación incluso de gobiernos socialistas, incidirá en el constitucionalismo con una actuación positiva de los poderes públicos y con una nueva función atribuida al derecho.

Se utilizará la igualdad como diferenciación, como método para alcanzar la igualdad como equiparación. Y finalmente, será un resultado importante del proceso de generalización la progresiva toma de conciencia de que la propiedad no puede ser una pretensión justificada, base ética de un derecho fundamental, dado que no se puede extender a todo el mundo, y eso es un privilegio pero, al carecer de la generalidad, no es un derecho igual de todos los seres humanos.

\section{Antecedentes de la desigualdad entre el hombre y la mujer}

La discriminación que ha existido en contra de la mujer, no sólo se ha reflejado en materia político-electoral; el hombre se ha encargado de diferenciarla y marginarla en diferentes ámbitos, como el familiar, económico, social, entre otros. En el presente capítulo entraremos a realizar un breve análisis de los antecedentes escritos que existen, a través de los cuales se asienta la desigualdad que ha existido entre el hombre y la mujer, tales como el Tratado de Conducta Moral y Costumbres de Francia del siglo XIV (Le Ménagier de Paris), el cual señalaba que

Cuando un hombre fuera reprendido en público por una mujer, tendrá derecho a golpearla con el puño y el pié y romperle la nariz para que así, desfigurada, no se deje ver, avergonzada de su faz. Y le estará bien merecido, por dirigirse al hombre con maldad y lenguaje osado.

Por su parte, la Constitución Nacional Inglesa del siglo XVIII, establecía expresamente que: "Todas las mujeres que sedujeran y llevaran al matrimonio a los súbditos de su majestad mediante el uso de perfumes, pinturas, dientes postizos, pelucas y relleno en caderas y pechos, incurrirían en delito de brujería y el casamiento quedaría automáticamente anulado".

Por lo que ve a los antecedentes escritos del Estado mexicano, la igualdad de la mujer se encontraba reducida a ser la compañera del 
hombre y encargada del hogar, tal y como lo podemos encontrar en el Código Civil Federal de 1928, el cual establecía en su artículo 163 que la mujer debía vivir al lado de su marido. En el artículo 168, se señalaba que estaría a cargo de la mujer la dirección y cuidado de los trabajos del hogar, y el artículo 169 señaló que la mujer podía desempeñar un empleo, ejercer una profesión, industria, oficio o comercio cuando ello no perjudique a la misión que le impone el artículo anterior.

La mujer casada guardaba una condición legal condicionada a la voluntad de su esposo. En el Código de Comercio mexicano reformado en 1954, su artículo $8^{\circ}$ señalaba que la mujer casada, mayor de dieciocho años, que tuviera autorización expresa del marido, otorgada en escritura pública, podría ejercer el comercio. Y sin la autorización de su marido lo podría ejercer en los casos de separación, ausencia, interdicto o privación de derechos civiles del mismo.

La ley de amparo, por su parte (en su artículo 17 derogado en 1986), establecía que cuando el agraviado se encontrara imposibilitado para promover el amparo, podría hacerlo cualquier otra persona a su nombre, "aunque sea menor de edad o mujer casada", estableciendo una marcada discriminación a la mujer casada, sujeta a la voluntad del marido, sin ser capaz de tomar decisiones. Con el estudio de dichos antecedentes, se puede advertir con facilidad la marcada desigualdad jurídica que ha existido entre el hombre y la mujer, quien quedaba sujeta al dominio y voluntad del hombre.

Actualmente en el artículo $4^{\circ}$ de la Constitución Política de los Estados Unidos Mexicanos, se establece la igualdad jurídica del hombre y la mujer cuando dispone que tanto el hombre como la mujer son iguales ante la ley, instituyendo de manera expresa la igualdad jurídica entre el hombre y la mujer; la igualdad entre sexos constituye un elemento fundamental de justicia, ya que con ella se evitan modos sutiles de discriminación, congruentes con las condiciones sociales de la mujer en nuestro medio (Izquierdo, 2007, 68-70).

Por lo que ve al derecho al sufragio, el 17 de octubre de 1953 el entonces presidente Adolfo Ruiz Cortines (1952-1958) reconoció el derecho de las mujeres. Se publicó en el Diario Oficial de la Federación un nuevo texto para el artículo 34 constitucional, en el que se establece que: "Son ciudadanos de la Republica los varones y las mujeres que, teniendo la calidad de mexicanos, reúnan, además, los siguientes requisitos: haber cumplido dieciocho años y tener un 
modo honesto de vivir", lo que significó la supresión de la adición al artículo 115, en la que el sufragio femenino se limitaba a las elecciones municipales (Cazarin, 2011, 19-20).

\section{Principio de igualdad}

Respecto al principio de igualdad, Ferrajoli $(2010,3)$ señala que es un principio complejo, que se ha estipulado para tutelar las diferencias y para oponerse a las desigualdades; hablar de conceptos como principio de igualdad, diferencias y desigualdades no solo son diferentes, sino que hasta opuestos. Por lo que refiere a las diferencias, existen diversas diferencias; en primer lugar la diferencia sexual, las diferencias de nacionalidad, de religión, de opiniones políticas o de otro tipo, que pueden consistir en la diversidad de nuestras identidades personales. Y por lo que se refiere a las desigualdades, contrario a las diferencias, consisten en la diversidad de condiciones económicas y materiales.

De lo que se puede advertir que tanto las diferencias como las desigualdades son hechos, mientras que el principio de igualdad es una norma que tiene el fin de proteger y valorizar las diferencias y de eliminar o cuando menos reducir las desigualdades; es decir, el principio de igualdad es un principio normativo que requiere la protección de las diferencias, tal como la diferencia de género. Precisamente porque somos diferentes por sexo, nacionalidad, idioma, religión, opiniones políticas, condiciones personales y sociales, porque la identidad de cada persona es diferente de la identidad de cualquier otra.

En tanto se estima necesario establecer y se establece, para los fines de la convivencia pacífica y de la legitimación democrática del sistema político, el principio de igualdad de las diferencias, es decir, de cada identidad personal, sin que se pueda permitir discriminar ni de hecho ni mucho menos de derecho. Definiendo Ferrajoli el principio de igualdad como "el igual valor asociado a todas las diferencias de identidad que hacen de toda persona un individuo diferente de todos los demás y de todo individuo una persona como las demás”; por lo tanto, el principio de igualdad es una norma la cual pretende que se reduzcan las desigualdades, coincidiendo con el principio de dignidad de las personas y con el carácter universal de los derechos humanos. Entonces, las desigualdades deben eliminarse, porque constituyen un 
obstáculo para el pleno desarrollo de la persona humana. La igualdad es, en suma, un principio complejo, que impone la tutela de las diferencias y la reducción de las desigualdades (Ferrajoli, 2010, 3).

Derecho a no ser discriminado que deriva del artículo $1^{\circ}$ de la Constitución Política de los Estados Unidos Mexicanos

El principio de igualdad consagrado en el último párrafo del artículo $1^{\circ}$ constitucional, se concibe como "Principio de no Discriminación"; en tal sentido, se sostiene la idea de que no puede hacerse distinción entre las personas por criterios de raza, religión, sexo, origen social, etc., al señalar:

Queda prohibida toda discriminación motivada por origen étnico o nacional, el género, la edad, las discapacidades, la condición social, las condiciones de salud, la religión, las opiniones, las preferencias sexuales, el estado civil o cualquier otra que atente contra la dignidad humana y tenga por objeto anular o menoscabar los derechos y libertades de las personas."

Los preceptos constitucionales que reconocen derechos de igualdad están encaminados a establecer bases elementales a fin de evitar la discriminación, impedir que las razones o pretextos que motivan que los hombres se discriminen unos a otros operen, neutralizando las causas de las disparidades. Su objetivo principal es evitar las desigualdades, dado que la discriminación niega el derecho a la igualdad por virtud de ella, por razones de sexo, raza, religión, edad u otras; se niega la posibilidad de ejercer un derecho a gozar de una libertad, cuando ellos son universales, encaminándose la norma a evitar ventajas o desventajas, reales o hipotéticas, basadas en alguna de las razones antes indicadas (Arteaga, 2009, 72-3).

\section{El derecho internacional, marco del desarrollo de la igualdad de género}

En el derecho internacional de los derechos humanos la igualdad de género y los derechos políticos de la mujer han sido temas fundamentales, que han orientado la celebración de diversos tratados internacionales, a partir de la carta de las Naciones Unidas; el pleno reconocimiento de los derechos de la mujer se vio impedido por las concepciones tradicionales respecto de su papel en la vida privada, 
como por la aparente neutralidad con que fue elaborada; las mujeres iniciaron su lucha por la obtención de igualdad mediante los derechos políticos, lo que se plasmó en las primeras convenciones sobre el derecho al voto de las mujeres (Serrano, 2009, 19).

La Convención sobre la eliminación de todas las formas de discriminación contra la mujer representó un paso importante hacia el pleno reconocimiento del derecho de la igualdad y la no discriminación en todos los ámbitos. El 18 de diciembre de 1979, la Asamblea General de las Naciones Unidas aprobó la Convención, que entró en vigor como tratado internacional el 3 de septiembre de 1981 tras su ratificación por 20 países. Esta Convención fue la culminación de más de 30 años de trabajo de la Comisión de la Condición Jurídica y Social de la Mujer, órgano creado en 1946 para seguir de cerca la situación de la mujer y promover sus derechos. La labor de la Comisión ha coadyuvado a poner de manifiesto todas las esferas en que a la mujer se le niega la igualdad con el hombre; estos esfuerzos en pro de la mujer han convergido en varias declaraciones y convenciones, de las cuales la Convención en estudio es el documento fundamental y más amplio.

La Convención ocupa un importante lugar, ya que incorporó la mitad femenina de la humanidad a la esfera de los derechos humanos en sus distintas manifestaciones; el espíritu de la Convención tiene su origen en los objetivos de las Naciones Unidas, entre lo que se encuentra reafirmar la fe en los derechos humanos fundamentales, en la dignidad y el valor de la persona humana y en la igualdad de derechos de hombres y mujeres. La Convención define el significado de la igualdad e indica cómo lograrla; en este sentido, la Convención establece no sólo una declaración internacional de derechos para la mujer, sino también un programa de acción para que los Estados partes garanticen el goce de esos derechos.

En su preámbulo la Convención reconoció explícitamente que "las mujeres siguen siendo objeto de importantes discriminaciones", y subraya que esa discriminación viola los principios de la igualdad de derechos y del respeto de la dignidad humana. Según el artículo $1^{\circ}$, por discriminación se entiende "toda distinción, exclusión o restricción basada en el sexo [...] en las esferas política, económica, social, cultural y civil o en cualquier otra esfera"; asimismo este instrumento internacional en su artículo $3^{\circ}$ obliga a los Estados partes que tomen 
todas las medidas apropiadas, incluso de carácter legislativo, para asegurar el pleno desarrollo y adelanto de la mujer, con el objeto de garantizarle el ejercicio y el goce de los derechos humanos y las libertades fundamentales en igualdad de condiciones con el hombre.

El tratado internacional en estudio, en general, distingue tres aspectos de la situación de la mujer: por una parte, el de los derechos civiles y la condición jurídica y social de la mujer que se abordan pormenorizadamente, pero además, y a diferencia de otros tratados de derechos humanos, la Convención se ocupa de los que tienen que ver con la reproducción humana y con las consecuencias de los factores culturales en las relaciones entre los sexos. Desde la aprobación en 1952 de la Convención sobre los Derechos Políticos de la Mujer no ha cesado el interés por los derechos fundamentales de la mujer en cuanto a su participación en la vida política, de ahí que disposiciones sobre este particular se hayan vuelto a incluir en el artículo $7^{\circ}$ de la presente convención, que garantiza a la mujer el derecho al voto, a ocupar cargos públicos y a ejercer funciones públicas; también se estipula la igualdad de derechos de la mujer para garantizarle la oportunidad de representar a su país en el plano internacional (artículo $8^{\circ}$ ).

El tercer cometido general de la Convención es el de ampliar la interpretación del concepto de los derechos humanos mediante el reconocimiento formal del papel desempeñado por la cultura y la tradición en la limitación del ejercicio por la mujer de sus derechos fundamentales. La cultura y la tradición se manifiestan en estereotipos, hábitos y normas que originan las múltiples limitaciones jurídicas, políticas y económicas al adelanto de la mujer. En el preámbulo de la Convención se destaca "que para lograr la plena igualdad entre el hombre y la mujer es necesario modificar el papel tradicional tanto del hombre como de la mujer en la sociedad y en la familia". En consecuencia, los Estados parte (como lo señala el artículo $5^{\circ}$ ) están obligados a coadyuvar a la modificación de los patrones socioculturales de conducta de hombres y mujeres para eliminar "los prejuicios y las prácticas consuetudinarias y de cualquier otra índole que estén basados en la idea de la inferioridad o superioridad de cualquiera de los sexos o en funciones estereotipadas de hombres y mujeres". En suma, la Convención proporciona un marco global para hacer frente a las diversas fuerzas que han creado y mantenido la discriminación basada en el sexo. 


\section{Cuotas de género}

En los años setenta, durante el auge del feminismo, el término género comenzó a usarse de manera sistemática, pero no fue hasta los años ochenta que la denominada "perspectiva de género" se consolidó como una visión significativa en la academia y en el ámbito de las políticas públicas. Finalmente, el debate sobre el significado y los alcances del concepto cobró más importancia a partir de la IV Conferencia Mundial sobre la Mujer, celebrada en Beijin en septiembre del 1995 (Zapata, 2010, 237).

Como se señaló en la introducción del presente ensayo, el sexo y el género son conceptos distintos, el primero es biológico y el segundo social. La división cultural entre hombre y mujeres no se desprende de una "naturaleza", sino de un hecho social y, por lo tanto, transformable. Definiendo Zapata al género "como la construcción cultural de la diferencia sexual” (Ibidem, 237).

Las cuotas de género se refieren a los porcentajes mínimos de candidaturas de uno y otro sexo con el objeto de garantizar un equilibrio en la representación popular; se trata de medidas compensatorias o afirmativas que se han presentado como necesarias ante las diversas barreras a la entrada al sistema político y la exclusión que históricamente han enfrentado las mujeres (De la Madrid, 2012, 34).

Las cuotas son el mecanismo de acción afirmativa más aplicado alrededor del mundo, y su objetivo es asegurar un nivel de participación mínimo para los grupos que, por uno u otro motivo, tienen dificultades insuperables para conseguirla. Su finalidad es asegurar a grupos sociales desfavorecidos al acceso a ciertos cargos o posiciones. En particular, las cuotas de género se han empleado para asegurar que una mayor cantidad de mujeres obtengan escaños en los parlamentos, mejorado así la proporcionalidad entre la población y sus representantes. Estas medidas especiales son de carácter temporal y duran solamente el tiempo necesario para que la balanza alcance el equilibrio deseado y los objetivos que se tenían en mente hayan sido cumplidos.

Es posible dividir los sistemas de cuota de género en tres tipos: las que aplican a la reserva de candidatos potenciales, las que aplican a las mujeres nominadas y las que aplican a las candidatas que resulten elegidas. La mayoría de los sistemas de cuotas alrededor del mundo, incluyendo al mexicano, pertenecen al segundo tipo. 
Otra posible clasificación es la que las divide en constitucionales, legislativas o de partido: la primera categoría goza del marco legal más absoluto, ya que se encuentra representada en la Constitución. Nepal, Filipinas, Uganda, Tanzania y Francia son ejemplos de países que han optado por este tipo de cuotas (y ahora con la reforma México, como más adelante se señalará).

Por último, pero no menos importante, las cuotas pueden dividirse en obligatorias y recomendadas: las cuotas obligatorias son las que, de no cumplirse, provocan algún tipo de sanción para los partidos, mientras que las cuotas recomendadas son menos eficaces, dado que se parecen más a una declaración de principios que a una verdadera norma. Si se opta por establecer estas últimas, los partidos gozan de un amplísimo margen de discrecionalidad para incumplirlas (Zapata, 2010, 243).

\section{SUP-JDC-I 2624/20 I I, una sentencia trascendental}

En nuestro país, una sentencia que marcó un parte aguas en el desarrollo de la equidad de género en el ámbito político-electoral, sin duda, es la sentencia que emitió la Sala Superior del Tribunal Electoral del Poder Judicial de la Federación al resolver el juicio para la protección de los derechos político electorales del ciudadano, bajo número de expediente SUP-JDC-12624/2011; es la misma que se originó al impugnarse el acuerdo emitido por el entonces Instituto Federal Electoral, donde se establecían los requisitos para el registro de candidaturas por mayoría relativa y representación proporcional por los partidos políticos para el proceso electoral del 2012, debido a que no existía claridad ni certeza en la norma reglamentaria que regía los procedimientos de elección internos de los partidos políticos, respecto a las reglas de excepción de la cuota de género.

Se promovió por mujeres militantes de diversas instituciones políticas, a las cuales la Sala Superior les reconoció el interés jurídico, puntualizando que, al ser militantes de instituciones políticas y con la sola aprobación del acuerdo en el que se establecen las cuotas de género tendientes a lograr un equilibrio en la participación de los hombres y mujeres en los cargos de diputadas y senadoras de mayoría relativa, contaban con el interés jurídico de impugnarlo, toda vez que las actoras pueden estar en la posibilidad real de ser postuladas a los cargos de elección y ser afectadas en sus derechos político-electorales. 
El entonces Instituto Federal Electoral, había determinado que la reserva de la ley respecto a que las cuotas de género podían incumplirse si había elecciones democráticas al interior de los partidos políticos para candidatos por el principio de mayoría relativa, a lo cual la Sala Superior, en lo relativo al cumplimiento de las cuotas de género que se establecían en el Código Electoral Federal, estableció lo que debía entenderse por "procedimiento democrático interno de los partidos", señalando que

si se considera que la esencia del establecimiento de la cuota de género tiene como objetivo el alcanzar la igualdad real en lo político electoral entre los hombres y mujeres, siendo que, en ese sentido, el análisis de casos concretos relativos a posibles vulneraciones al derecho de la igualdad entre los géneros, no debe realizarse sobre la base de entendimientos o interpretaciones implícitas de los hechos, pues dicho proceder es contrario al criterio que ordena potencializar los derechos humanos y, al contrario sensu, interpretar de forma restrictiva las excepciones o límites a los mismos. Este criterio lo retomó del principio pro homine, establecido en el artículo 1, párrafo 2 de la Constitución Federal, "el cual dispone que las normas relativas a los derechos humanos, se deben interpretar favoreciendo en todo tiempo, a las personas, la protección más amplia

\section{Asimismo indicó que}

los límites constitucionales a la igualdad entre los géneros, en el contexto del registro de candidaturas a diputados y senadores por el principio de mayoría relativa, no deben ser interpretados de tal manera que se permita una limitación a tales derechos, por el contrario, es preciso constreñir a su más mínima dimensión, la limitación de que se trata, de tal manera que no se encuadren en la misma, más supuestos que los mínimos para no hacer nugatorio en la realidad ese tipo de derechos".

Por otra parte, “por lo que toca a la cualidad 'democrática' de los procedimientos para la designación de candidatos a diputados y senadores de mayoría relativa, se puede asumir que, en principio, está dada por los propios estatutos de los partidos políticos”. 
Por lo que, la determinación de la autoridad administrativa no maximizaba ni potencializaba los derechos de las mujeres. Indicó que el Instituto Federal Electoral no fue exhaustivo, porque no analizó el contenido de los estatutos de todos los partidos políticos. Agrega que, de haberlo hecho, habría concluido que ninguno contiene una definición de "procesos internos de elección democrática" y que ante tal circunstancia, la responsable debió hacer una interpretación conforme del artículo 219 del Código Federal de Instituciones y Procedimientos Electorales, procurando la máxima expansión de los derechos de las mujeres, en lugar de hacer nugatorio lo establecido en el párrafo $1^{\circ}$ del artículo aludido.

La Sala Superior señaló que, si la ley buscaba garantizar la equidad de género, no debía ser sólo una recomendación a los partidos políticos, sino una obligación que tenían que respetar. Asimismo, garantizó que la equidad se reflejara en el ejercicio del cargo, así que, todos los suplentes que integren el $40 \%$ de las fórmulas de candidatos del mismo género debían pertenecer al mismo género que sus propietarios. Por lo que para cumplir con el principio de equidad de género, debía aplicarse para todos los diputados y senadores, independientemente del principio por el cual hayan sido elegidos, por mayoría relativa o por representación proporcional. Esta determinación sin duda ha servido como base a las reformas llevadas a cabo en el presente año (2014) en materia político-electoral.

En este sentido, el tribunal realizó una interpretación armónica conforme a la Constitución y los tratados internacionales, que prevén el derecho de todo ciudadano de tener acceso a cargos de elección popular, en condiciones generales de igualdad y bajo una perspectiva de equidad de género. Asimismo, atendiendo al bloque de constitucionalidad en materia de derechos humanos al advertir que la equidad de género y las condiciones de igualdad para el acceso a la representación política constituían principios democráticos que perseguían un fin constitucional, consistente en la composición democrática de los órganos del poder público, con una integración equitativa entre ambos géneros, por lo tanto, la equidad en el acceso a las candidaturas a cargos de elección popular solo resultaba eficaz si se tomaban las medidas razonables y necesarias para propiciar que el género que se encuentra en minoría, integrara dichas candidaturas, y con ello se generaba la posibilidad real de acceder a la representación política (Bustillo, 2013, 32-7). 
Las promoventes de dicho juicio manifiestan haber celebrado la sentencia 12624 y saludado los premios y reconocimientos otorgados al Tribunal, entre otros, por la Organización de las Naciones Unidas (ONU) y por la Women's Link Worldwide, organización que le entregó el Mallete de Bronce al reconocer su actitud democrática y no discriminatoria contra las mujeres (Moreno, 2013, 55).

\section{Análisis de las cuotas de género en el desarrollo democrático mexicano}

Tanto en el ámbito nacional como internacional, las cuotas de género surgieron como una medida para encontrar un equilibrio en la participación de mujeres y hombres en los órganos de toma de decisiones. En México el desarrollo de la incorporación de la vida democrática de la mujer encuentra antecedente en 1996, ya que se fijó un límite de $70 \%$ de legisladores de un mismo género y en 2007 se estableció que las candidaturas para integrar el poder legislativo debían de integrarse, cuando menos de un $40 \%$ por personas de un mismo sexo.

Como un avance significativo se tiene el proceso electoral 20112012, del cual se suscitaron controversias jurisdiccionales, resolviéndose en una de ellas por el Tribunal Electoral, que los partidos políticos y coaliciones, nombraran candidatos propietarios y suplentes de un mismo género para diputados y senadores (como ya se señaló en párrafos que anteceden). No sólo los partidos políticos debían cumplir con dicha resolución, y en aquel momento el entonces Instituto Nacional Electoral IFE emitió un acuerdo para cumplir con el mandato del Tribunal, teniéndose como resultado de estas medidas temporales que el porcentaje de mujeres que integraban el Congreso Federal alcanzó un 35.99\%, lo que implicó que hubiera 185 mujeres diputadas y 42 senadoras, lo cual implicó 227 curules ocupadas por mujeres, representando un logro histórico.

El hecho de haber cumplido con las cuotas de género no sólo implicó un aumento con relación a la integración de las cámaras, sino un avance en la implementación de acciones a favor de la igualdad y la eliminación de discriminación.

A nivel local, aunque ha habido avances, el panorama es distinto: el porcentaje de mujeres diputadas pasó de 9,6 en 1991 a 23,6\% en 2012, lo que implicó que 8 de las 32 legislaturas locales estuvieran integradas por mujeres en $30 \%$ o más. 
El Tribunal Electoral del Poder Judicial de la Federación, en la aplicación de la cuota de género, ha distinguido cuatro etapas, marcadas por diferentes reglas de aplicabilidad y proporción de la cuota de género que afectaban la efectividad de la medida. En la primera etapa (1993-2002), la cuota era solamente indicativa para los partidos políticos y la participación de las mujeres en la Cámara de Diputados oscilaba alrededor de $15 \%$, sin que se estuviera logrando su finalidad. En la segunda etapa (2002-2007), la cuota fue obligatoria, el umbral de $30 \%$ permitió un pequeño incremento de participación femenina, esto es, alrededor del $23 \%$. En la tercera etapa (2007-2011), con el incremento del porcentaje de la cuota obligatoria al $40 \%$, se alcanzó la representación de las mujeres de $28 \%$. Con el control judicial de la Sala Superior del Tribunal Electoral del Poder Judicial de la Federación y la sentencia SUP-JDC-12624/2011, se marcó la cuarta etapa de la cuota, cuando ésta logró mayor efectividad, alcanzando el 37\% de representación femenina en la Cámara de Diputados y, por primera vez, superando el umbral mínimo necesario para que la presencia de un grupo en un cuerpo colegiado alcance los niveles necesarios para conseguir influencia en la toma de decisiones, que los estudios ubican en el $30 \%$.

La obligación de acatar la cuota de género obedecía a un mandato legal de garantizar que ningún género tuviera más de $60 \%$ de candidaturas en las elecciones legislativas.

\section{La paridad de género en la reforma político-electoral de 20 I4}

El pasado 31 de enero de 2014 fue promulgada, por el Presidente de la República, la reforma político electoral, la cual entre otras cuestiones prevé que los partidos políticos deberán garantizar la paridad entre géneros en candidaturas a legisladores federales y locales, previo al estudio de esta reforma, a través de la cual se hace un reconocimiento expreso a la igualdad de géneros en la participación de las decisiones políticas del país, derecho pasivo al sufragio (en cuanto a las cuotas de género); es preciso realizar un breve análisis de lo que la igualdad jurídica se refiere. Al respecto, Ferrajoli (2010) resume la igualdad jurídica como igualdad en los derechos fundamentales, donde interviene el universalismo de tales derechos, tanto de libertad como sociales, entendiendo por universalismo no un consenso universal con relación a los derechos, sino el 
hecho de que ellos, desde los derechos de libertad hasta los derechos sociales, contrariamente a los derechos patrimoniales, en los que se funda la desigualdad jurídica, corresponden igual y universalmente a todos. Decir que un derecho es fundamental es decir que todos los individuos son, en medida igual, titulares de él. Así, se deriva dos consecuencias: una relativa a las dimensiones de la igualdad jurídica, y la otra a la distinción entre diferencias, desigualdades y discriminaciones. En el paradigma lockeano, y después en el de las primeras constituciones liberales, la igualdad se amplia para llegar a ser la garantía de los derechos de libertad y de autonomía particular. La igualdad jurídica no será otra cosa que la idéntica titularidad y garantía de los mismos derechos fundamentales, independientemente del hecho, y al contrario, las personas son diferentes de hecho pero no de derecho, por las desigualdades, estas últimas antijurídicas, que se producen mediante la violación del principio de igualdad, por las discriminaciones de sus diferencias. (2010, p. 14).

La igualdad puede resultar siendo un principio normativo, inefectiva en grados diversos, ya sea en su dimensión formal como en sus mínimos sustanciales, en virtud de las múltiples "discriminaciones" y "desigualdades" antijurídicas que la puedan violar por medio de lesiones de hecho de los derechos fundamentales. Se le llama discriminaciones a las violaciones del primer tipo, y seguir llamando desigualdades, agravadas naturalmente por su ilegitimidad, a las violaciones del segundo tipo, las unas y las otras generadas por la brecha, de que la política y la ciencia jurídica deben hacerse cargo, entre la normatividad y efectividad del principio de igualdad (Ferrajoli, 2010, 15).

Con la reforma constitucional en materia político-electoral efectuada en el año 2014, se da un paso determinante respecto a la igualdad jurídica de los géneros en materia político-electoral. El derecho de la participación de la mujer en la vida política del país se incorpora en el rango constitucional, imponiendo a los partidos políticos la obligación de garantizar la paridad de género, es decir, que se integren las listas con el $50 \%$ de hombres y $50 \%$ de mujeres en la postulación de candidaturas a legisladores federales y locales. El artículo 41 base I determina que

los partidos políticos tienen como fin promover la participación del pueblo en la vida democrática, contribuir a la integración de los órganos de representación política y como organizaciones de ciudadanos, hacer 
posible el acceso de éstos al ejercicio del poder público, de acuerdo con los programas, principios e ideas que postulan y mediante el sufragio universal, libre, secreto y directo, así como las reglas para garantizar la paridad entre los géneros, en candidaturas a legislaturas federales y locales $[\ldots]$.

A raíz de dicha reforma, nacen diversas leyes reglamentarias de sus disposiciones, como la Ley General de los Partidos Políticos, misma que en sus artículos $3.3^{\circ}, 4^{\circ}$ y $5^{\circ}$ establece que los partidos deben asegurar la participación efectiva de ambos géneros tanto en la integración de sus órganos como en la postulación de candidatos. Para lo cual, cada partido puede determinar los criterios que garanticen la paridad en las candidaturas, tomando en cuenta la expectativa de ganar la elección.

Otra de las leyes que nació para regular las nuevas disposiciones constitucionales es la Ley General de Instituciones y Procedimientos Electorales, misma que en sus disposiciones establece fórmulas para garantizar el respeto a dicha paridad de género. Un ejemplo de ello es el artículo 232 en su punto tres, el cual señala que las listas de candidatos a los cargos de elección popular para la integración del Congreso de la Unión, los Congresos de los Estados y la Asamblea Legislativa del Distrito Federal deberán ser integradas por el 50\% de candidatas mujeres y el $50 \%$ de hombres. Por su parte, el artículo 14 de dicha ley, en su punto cuatro, establece que las fórmulas de candidatos por mayoría relativa y por representación proporcional deben ser integradas por personas del mismo género.

Adicionalmente, la ya señalada Ley de Partidos, en su artículo 3.5, establece que ningún partido podrá postular a los candidatos de uno de los géneros exclusivamente en los distritos dónde han obtenido la votación más baja.

Por su parte, la Sala Superior del Tribunal Electoral del Poder Judicial de la Federación mediante la tesis IX/2014, sostuvo que la cuota de género, para que resulte efectiva, debe generar sus efectos no sólo al momento del registro de la lista de candidaturas, sino también al momento de la asignación de curules de representación proporcional. En desarrollo de esa línea argumentativa, la Sala Regional Monterrey en la sentencia SM-JRC-14/2014sentencia SM-JRC-14/2014, además de atender el principio de subrepresentación, determinó ajustar la asignación de curules de representación 
proporcional en el caso del Congreso del Estado de Coahuila, seleccionando dentro del orden de ubicación en la lista a la primera mujer, para garantizar paridad en la integración del Congreso del Estado; con ello, el Congreso se integró con 13 diputadas y 12 diputados.

En esa sentencia, la Sala Monterrey determinó que la postulación paritaria de candidatos para la integración del Congreso debe traducirse en un mecanismo que permita a las mujeres acceder de forma efectiva a los cargos públicos, incluso a pesar del orden que establezcan los partidos políticos en sus listas de representación proporcional, sin que esto signifique una violación a la autodeterminación de los partidos. Sostuvo también que con ello

no se priva de un derecho adquirido al candidato que ocupe el primer lugar de la lista, pues con independencia de la posición que tenga en el listado, su derecho a detentar un escaño estará limitado en la medida que su nombramiento como diputado impida que en la integración del Congreso del Estado, se respete el principio de igualdad y así como las acciones afirmativas en materia de equidad de género.

\section{La paridad de género en las fórmulas de candidatos indepen- dientes al cargo de diputado federal}

Con la reforma político electoral, se reconoció el derecho de los ciudadanos a ser candidatos independientes en ciertos cargos de elección popular; la Ley General de Instituciones y Procedimientos Electorales, en su título séptimo, regula dicho derecho, designando fórmulas para la integración de la participación de los géneros. En primer lugar, es importante señalar que cada fórmula deberá integrarse por personas del mismo género, como lo establece el artículo 14.5 de la Ley General de Instituciones y Procedimientos Electorales y que, para la elección de senadores, cada fórmula deberá ser de género distinto (artículo 364.1). Eso significa que la fórmula que se registre para los candidatos a diputados debe quedar integrada por dos mujeres o dos hombres (propietario y suplente). En caso de la elección de senadores, en la que es necesario registrar una lista de dos fórmulas, una debe quedar integrada por dos mujeres y la otra por dos hombres, sin importar el orden, con lo qué, ahora legalmente, se evitan prácticas del pasado a través de las cuales mañosamente 
se nombraba un suplente de otro sexo, para que al final el titular renunciara y en automático el suplente subía al cargo, dándose una franca violación a la cuota de género que se tenía que cumplir por parte de los partidos políticos.

El esquema adoptado no limita el número de candidaturas independientes que pueden registrarse a cada cargo de elección popular, pero condiciona el obtener el registro al cumplimiento de una serie de requisitos y establece un proceso de registro.

Con la finalidad de ilustrar las reformas legales efectuadas en 2014 en materia de paridad de género, a continuación se presenta un cuadro comparativo del cómo se encontraba reglamentado las cuotas de género en el derogado Código Federal de Instituciones y Procedimientos Electorales, y cómo se encuentran actualmente reglamentadas en la nueva Ley General de Instituciones y Procedimientos Electorales.

Cuadro I - Cuotas de género en la Ley General de Instituciones y Procedimientos Electorales y en el Código Federal de Instituciones y Procedimientos Electorales.

\begin{tabular}{|c|c|}
\hline LGIPE & COFIPE \\
\hline $\begin{array}{l}\text { Ley General de Instituciones y Proce- } \\
\text { dimientos Electorales (publicada en el } \\
\text { Diario Oficial de la Federación el } 23 \text { de } \\
\text { mayo de 2014). }\end{array}$ & $\begin{array}{l}\text { Código Federal de Instituciones y Proce- } \\
\text { dimientos Electorales (derogada, con la } \\
\text { entrada en vigor de la LGIPE). }\end{array}$ \\
\hline Artículo I4 & Artículo 14 \\
\hline $\begin{array}{l}\text { 4. En las listas a que se refieren los } \\
\text { párrafos anteriores, los partidos polí- } \\
\text { ticos señalaran el orden en que deben } \\
\text { aparecer las fórmulas de candidatos. En } \\
\text { las fórmulas para Senadores y Diputados, } \\
\text { tanto en el caso de mayoría relativa, } \\
\text { como de representación proporcional, } \\
\text { los partidos políticos deberán integrar- } \\
\text { los por personas del mismo género. }\end{array}$ & $\begin{array}{l}\text { 4. En las listas a que se refieren los } \\
\text { párrafos anteriores, los partidos polí- } \\
\text { ticos señalaran el orden en que deben } \\
\text { aparecer las fórmulas de candidatos. }\end{array}$ \\
\hline $\begin{array}{l}\text { 5. En el caso de las candidaturas inde- } \\
\text { pendientes, las fórmulas deberán estar } \\
\text { integradas por personas del mismo } \\
\text { género. }\end{array}$ & \\
\hline
\end{tabular}




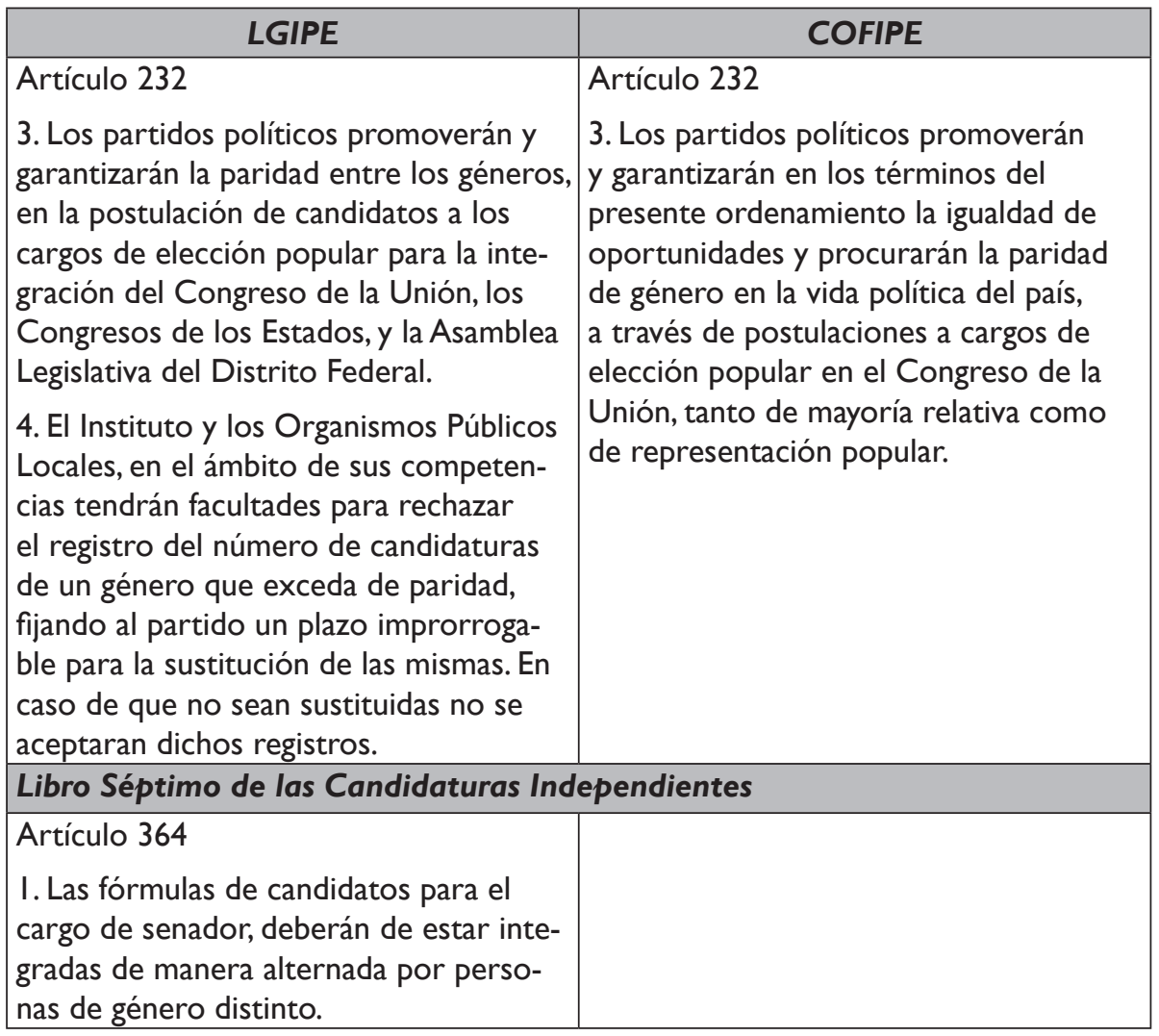

Fuente: México (2014) y México (2008).

\section{Conclusiones}

Con la reforma político-electoral efectuada en 2014, se da un paso determinante respecto a la igualdad jurídica de los géneros en materia político-electoral, ya que se incorpora a nivel de rango constitucional la obligación a los partidos políticos de garantizar la paridad de género, esto es, integrar las listas con el $50 \%$ de hombres y $50 \%$ de mujeres en la postulación de candidaturas a legisladores federales y locales. Con la reforma del artículo 41 de la Constitución Federal, las nuevas disposiciones de la Ley General de Instituciones y Procedimientos Electorales, la Ley General de Partidos Políticos y el ejercicio interpretativo realizado por el Tribunal Electoral del Poder Judicial de la Federación, se está construyendo un nuevo camino, donde ya se puede hablar de igualdad jurídica del hombre y la mujer en los derechos humanos 
del ámbito político-electoral, camino que debe respetarse por los actores que intervienen en el marco político mexicano, ya que sólo con el respeto al nuevo derecho electoral se lograra una verdadera equidad de género.

\section{Referencias}

ARTEAGA, N. E. (2009). Garantías individuales. México: Oxford.

BARRELES, A. P. B.; GÓMORA, J. S. (2013). Participación política de la mujer en México: acciones afirmativas y partidos políticos. Tribunal Electoral del Poder Judicial de la Federación, México, vol. 1, n. 12, jul/dic.

BUSTILLO, R. M. (2013). Lineas jurisprudenciales - el control de convencionalidad: la idea del bloque constitucional y su relación con el control de constitucionalidad en materia electoral. México: Tribunal Electoral del Poder Judicial de la Federación, p. 32-37.

CAZARIN, A. M. (2011). Democracia género y justicia electoral en México. México: Tribunal Electoral del Poder Judicial de la Federación.

CONVENCIÓN SOBRE LA ELIMINACIÓN DE TODAS LAS FORMAS DE DISCRIMINACIÓN. (2010). Panamá. Protocolo facultativo de la Convención sobre la eliminación de todas las formas de discriminación contra la mujer. Disponible en: [http://www.unicef.org/panama/spanish/MujeresCo_web.pdf]. Visitado el 24 de julio de 2015.

DE LA MADRID, R. R. (2012). Reporte sobre la discriminación en México. Derechos Políticos, Consejo Nacional para Prevenir la Discriminación. Disponible en: [www.conapred.org.mx/userfiles/files/Reporte_D-derechospolíticos_INACCSS. pdf]. Visitado el 9 de diciembre de 2014.

FERRAJOLI, L. (2010). El principio de igualdad y la diferencia de género. In: CRUZ, J. A. P.; VÁZQUEZ, R. (coords.), Debates constitucionales sobre derechos humanos de las mujeres. México: Fontamara y Suprema Corte de Justicia de la Nación.

IZQUIERDO, M. E. M. (2007). Garantías individuales. México: Oxford.

MÉXICO. (1917). Constitución Política de los Estados Unidos Mexicanos. Constitución publicada en el Diario Oficial de la Federación el 5 de febrero de 1917. Disponible en: [http://www.diputados.gob.mx/LeyesBiblio/htm/1.htm]. Visitado el 24 de julio de 2015.

MÉXICO. (1928). Código Civil Federal: 1928. Disponible en: [http://www.diputados.gob.mx/LeyesBiblio/ref/ccf/CCF_orig_26may28_ima.pdf]. Visitado el 24 de julio de 2015.

MÉXICO. (1936). Ley de Amparo, reglamentaria de los artículos 103 y 107 de la Constitución Politica de los Estados Unidos Mexicano. Disponible en: [http:// 
www.ordenjuridico.gob.mx/Publicaciones/CDLeyesyReg05/pdf/L-9.pdf]. Visitado el 24 de julio de 2015.

MÉXICO. (2008). Código Federal de Instituciones y Procedimientos Electorales. Disponible en: [http://norma.ife.org.mx/documents/27912/234587/2008_COFIPE. pdf/56e9c54e-2481-48f9-9122-a8231dc3806b]. Visitado el 24 de julio de 2015.

MÉXICO. (2011). Sentencia SUP-JDC-12624/2011. Disponible en: [http://www. te.gob.mx/Informacion_juridiccional/sesion_publica/ejecutoria/sentencias/SUPJDC-12624-2011.pdf]. Visitado el 24 de julio de 2015.

MÉXICO. (2014). Ley General de Instituciones y Procedimientos Electorales. Disponible en: [http://www.diputados.gob.mx/LeyesBiblio/pdf/LGIPE_100914. pdf]. Visitado el 24 de julio de 2015.

MÉXICO. (2014). Ley General de Partidos Políticos. Disponible en: [http://www.diputados.gob.mx/LeyesBiblio/pdf/LGPP_100914.pdf]. Visitado el 24 de julio de 2015. MÉXICO. (2014). Sentencia SM-JRC-14/2014. Disponible en: [http://portales.te. gob.mx/genero/sites/default/files/SM-JRC-0014-2014.pdf]. Visitado el 24 de julio de 2015.

MORENO, M. de los A. U. (2013). Igualdad de género en la política. In: ALCOCER, J. V. (ed.). Cuota de género, una sentencia histórica. México: Instituto Electoral y de Participación Ciudadana del Estado de Jalisco y Nuevo Horizonte.

PECES-BARBA, G. (2004). Lecciones de derechos fundamentales. Madrid: Dykinson. SERRANO, S. (2009). Igualdad de género y derechos políticos de la mujer en el Derecho Internacional y los Derechos Humanos. In: Equidad de género y derecho electoral mexicano. México: Tribunal Electoral del Poder Judicial de la Federación.

ZAPATA, M. I. (2010). Las cuotas de género en México: alcances y retos. In: CRUZ, P. J. A.; VÁZQUEZ, R. (coords.). Debates constitucionales sobre derechos humanos de las mujeres. México: Fontamara y Suprema Corte de Justicia de la Nación. 